\title{
Tachycardia-induced cardiomyopathy in the ovine heart: Mitral annular dynamic three-dimensional geometry
}

\author{
Tomasz A. Timek, MD \\ Paul Dagum, MD, PhD \\ David T. Lai, FRACS ${ }^{a}$ \\ David Liang, MD, PhD \\ George T. Daughters, $\mathrm{MS}^{\mathrm{a}, \mathrm{c}}$ \\ Frederick Tibayan, $\mathrm{MD}^{\mathrm{a}}$ \\ Neil B. Ingels, Jr, $\mathrm{PhD}^{\mathrm{a}, \mathrm{c}}$ \\ D. Craig Miller, MD
}

From the Department of Cardiothoracic Surgery, ${ }^{\text {a }}$ Division of Cardiovascular Medicine, ${ }^{\mathrm{b}}$ Stanford University School of Medicine, Stanford, Calif, and Laboratory of Cardiovascular Physiology and Biophysics, ${ }^{\text {c }}$ Research Institute of the Palo Alto Medical Foundation, Palo Alto, Calif.

Supported by grants HL-29589 and HL67025 from the National Heart, Lung, and Blood Institute. Drs Timek, Tibayan, and Dagum were also supported by NHLBI INRSA grants HL-10452, HL-67563, and HL-10000, respectively. Drs Timek, Lai, Dagum, and Tibayan are Carl and Leah McConnell 1 Cardiovascular Surgical Research Fellows. Dr Timek was also a recipient of the Thoracic Surgery Foundation Research Fellowship Award. Dr Lai was supported by a fellowship from the American Heart Association, Western States Affiliate.

Received for publication April 8, 2002; revisions requested June 12, 2002; revisions received July 15,2002 ; accepted for publication July 18, 2002.

Address for reprints: D. Craig Miller, MD, Department of Cardiothoracic Surgery, Falk Cardiovascular Research Center, Stanford University School of Medicine, Stanford, CA 94305-5247 (E-mail: dcm @leland. stanford.edu).

J Thorac Cardiovasc Surg 2003;125:315-24

Copyright $\left({ }^{\circ} 2003\right.$ by The American Association for Thoracic Surgery

$0022-5223 / 2003 \$ 30.00+0$

doi: $10.1067 / \mathrm{mtc} .2003 .80$
Background: Ring annuloplasty has been used to correct annular dilatation and mitral regurgitation in dilated cardiomyopathy, but little is known about the dynamic precise 3-dimensional geometry of the mitral annulus in this condition.

Methods: Nine sheep had radiopaque markers sewn to the mitral annulus, creating 8 distinct segments beginning at the posterior commissure (segments 1-4, septal mitral annulus; segments 5-8, lateral mitral annulus). Biplane videofluoroscopy and transesophageal echocardiography were performed before and after rapid pacing (180-230 $\mathrm{min}^{-1}$ for $15 \pm 6$ days) sufficient to develop tachycardia-induced cardiomyopathy and mitral regurgitation. Mitral annular segment contraction was defined as the percentage difference between maximum and minimum lengths. Mitral annular area and mitral annular septal-lateral and commissure-commissure diameters and 3-dimensional shape were determined from marker coordinates.

Results: With tachycardia-induced cardiomyopathy, end-diastolic mitral annular area, septal-lateral diameter, and commissure-commissure diameter increased by $36 \% \pm 14 \%, 25 \% \pm 12 \%$, and $9 \% \pm 5 \%$, respectively $(P<.01)$, whereas mitral regurgitation increased from $0.3 \pm 0.2$ to $2.2 \pm 0.9(P<.0001)$. All annular segments dilated at end-diastole with tachycardia-induced cardiomyopathy, except the segment between the midseptal annulus and the left fibrous trigone. Annular segment contraction was significantly decreased with tachycardia-induced cardiomyopathy in the lateral, but not in the septal, regions. Three-dimensional reconstruction of annular shape revealed a saddle shape of the annulus at baseline; this shape was also measured with tachycardia-induced cardiomyopathy, but there was some flattening of the septal annulus.

Conclusions: With tachycardia-induced cardiomyopathy, the mitral annulus dilated substantially, being more in the septal-lateral than in the commissure-commissure dimension. Greater annular segmental dilatation and decreased contraction occurred in the lateral annulus. The saddle shape of the annulus was retained but flattened.

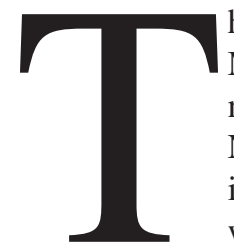

he mitral annulus deforms dynamically during the cardiac cycle. ${ }^{1}$ Mitral annular expansion facilitates filling in diastole, whereas annular reduction aids leaflet coaptation and normal closure in systole. Normal annular dynamics are altered by hemodynamic conditions, ${ }^{1}$ ischemia, ${ }^{2}$ and atrial contraction pattern. ${ }^{3,4}$ Mitral annular dilatation was suggested by Boltwood and colleagues ${ }^{5}$ to be the primary cause of functional mitral regurgitation (MR) in patients with dilated cardiomyopathy, and recent echocardiographic studies have reported altered 3-dimensional (3-D) annular 


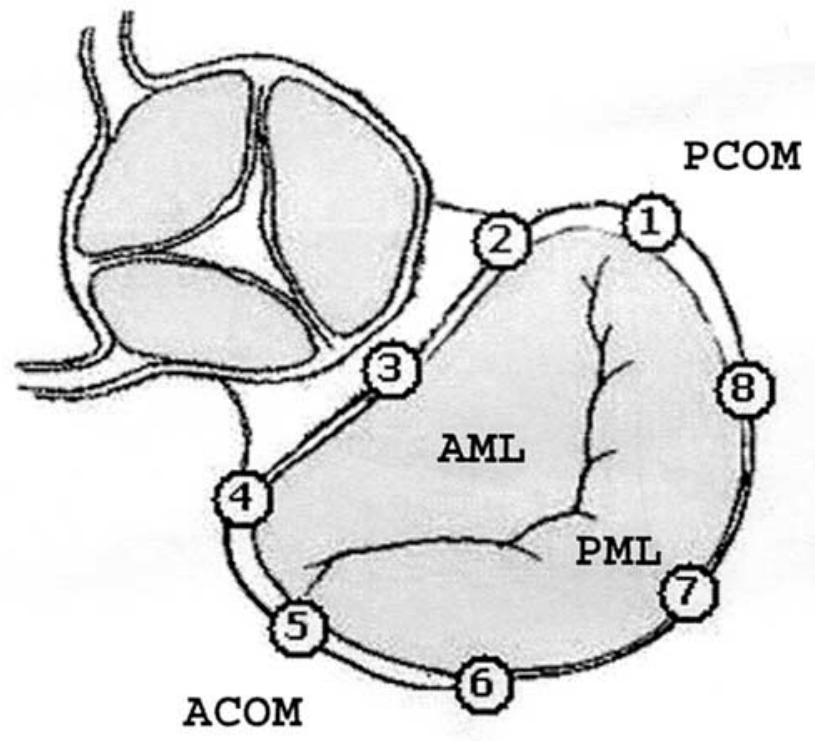

Figure 1. Schematic representation of the mitral annular marker array used in the study. Markers 2 and 4 correspond to the right and left fibrous trigones, respectively. ACOM, Anterior commissure; PCOM, posterior commissure; $A M L$, anterior mitral leaflet; $P M L$, posterior mitral leaflet.

dynamics in patients with dilated ${ }^{6}$ and ischemic ${ }^{7}$ cardiomyopathy, which could contribute to mitral insufficiency. Although these studies provide important insights into mitral annular physiology in cardiomyopathic states, precise measurements of annular dynamic 3-D geometry in end-stage dilated ventricles do not exist. Even though ring annuloplasty can abolish MR in patients with dilated cardiomyopathy ${ }^{8}$ more information is needed. Such data might lead to improved prosthetic ring design and development of new annular procedures that would reliably correct MR in a durable fashion by using more physiologic repair techniques.

Using myocardial marker technology, we investigated precise mitral annular 3-D dynamic geometry before and after the development of tachycardia-induced cardiomyopathy (TIC) in an ovine model. This model of end-stage heart failure has been shown to result in $\mathrm{MR}^{9}$ and is associated with the hemodynamic ${ }^{10,11}$ and neurohumoral ${ }^{12}$ changes seen in human heart failure.

\section{Methods}

\section{Surgical Preparation}

The surgical preparation for myocardial marker insertion has been described in detail previously, ${ }^{3}$ and therefore it will be summarized only briefly here. Nine adult sheep were premedicated with ketamine $(25 \mathrm{mg} / \mathrm{kg}$ administered intramuscularly) for venous and arterial line placement and monitored, and anesthesia was induced with sodium thiopental $(6.8 \mathrm{mg} / \mathrm{kg}$ administered intravenously). The animals were intubated and mechanically ventilated (Servo
Anesthesia Ventilator, Siemens-Elema AB), and anesthesia was maintained with inhalational isoflurane (1\%-2.2\%). A left thoracotomy was performed. Eight miniature tantalum markers (inner diameter, $0.8 \mathrm{~mm}$; outer diameter, $1.3 \mathrm{~mm}$; length, 1.5-3.0 $\mathrm{mm}$ ) were inserted beneath the left ventricular (LV) epicardial surface along 4 equally spaced longitudinal meridians for LV volume determination, with one marker placed at the LV apex. The right atrium and the descending thoracic aorta were cannulated after heparinization $(300 \mathrm{IU} / \mathrm{kg})$. After establishment of cardiopulmonary bypass and cardioplegic arrest, 8 tantalum markers were sutured to delineate the circumference of the mitral annulus (Figure 1, markers 1-8, with markers 2 and 4 corresponding to the right and left fibrous trigones, respectively). The animal was rewarmed, the atriotomy was closed, the crossclamp was removed, and, after resuscitation, the animal was weaned from bypass. A micromanometer pressure transducer (PA4.5-X6, Konigsberg Instruments, Inc) was placed in the LV chamber through the apex. A unipolar pacing lead was sewn to the LV epicardium.

\section{Experimental Protocol}

After $6 \pm 1$ days (mean $\pm 1 \mathrm{SD}$ ), each animal was taken to the cardiac catheterization laboratory, sedated with ketamine (1-4 $\mathrm{mg} \times \mathrm{kg}^{-1} \times \mathrm{h}^{-1}$ of intravenous infusion) and diazepam (5-mg intravenous bolus as needed), intubated, and mechanically ventilated (veterinary anesthesia ventilator 2000, Halowell EMC). An intravenous infusion of esmolol $\left(20-50 \mu \mathrm{g} \times \mathrm{kg}^{-1} \times \mathrm{min}^{-1}\right)$ was used to minimize reflex sympathetic responses. Simultaneous biplane videofluoroscopy and hemodynamic data recordings were obtained during stable steady-state conditions. Transesophageal Doppler echocardiography was performed by an experienced echocardiographer to assess MR. MR was graded according to the extent and width of the regurgitant jet and categorized as none $(0)$, mild $(+1)$, moderate $(+2)$, moderate to severe $(+3)$, or severe $(+4)$.

\section{Data Acquisition}

Images were acquired with the animal in the right lateral decubitus position by using a Phillips Optimus 2000 biplane Lateral ARC 2/Poly DIAGNOST C2 system (Phillips Medical Systems) with the image magnification set in the 9-inch fluoroscopic mode. Marker image positions from the 2 simultaneous radiographic views were digitized and merged to yield 3-D coordinates for each radiopaque marker every $16.7 \mathrm{~ms}$ with custom-designed software. ${ }^{13}$ Synchronized ascending thoracic aortic pressure, LV pressure, and electrocardiographic voltage signals were recorded simultaneously during videographic data acquisition.

\section{Pacing Protocol}

After baseline data acquisition, while still sedated, a rapid-pacing pulse generator (Prodigy S 8164, Medtronic Medical) was inserted into a subcutaneous pocket and connected to the previously externalized LV electrode, and the animal was recovered. Rapid pacing was initiated 24 hours later. During the pacing period, interval transthoracic echocardiography was performed to assess LV dimensions, systolic LV performance, and MR (with the pacemaker temporarily off) to guide pacing rate adjustments. The end point for cessation of pacing was development of clinically significant MR, LV dilatation, and heart failure. The first 2 animals were 
paced at $180 \mathrm{~min}^{-1}$, and subsequent animals were paced at 230 $\min ^{-1}$, which resulted in faster development of heart failure and MR. The average pacing period was $15 \pm 6$ days. Then the animals were returned to the catheterization laboratory with the pacemaker turned off before the study. Hemodynamic, marker, and echocardiographic data were again acquired.

All animals received humane care in compliance with the "Principles of Laboratory Animal Care" formulated by the National Society for Medical Research and the "Guide for the Care and Use of Laboratory Animals" prepared by the Institute of Laboratory Animal Resources, National Research Council, and published by the National Academy Press, revised 1996. This study was approved by the Stanford Medical Center Laboratory Research Animal Review Committee and conducted according to Stanford University policy.

\section{Data Analysis}

Three consecutive steady-state beats during normal sinus rhythm before and after rapid pacing were averaged and defined as baseline and TIC data for each animal. During each cardiac cycle, the time of end systole (ES) was defined as the videofluoroscopic frame containing the point of peak negative LV rate of pressure decrease $(-\mathrm{dP} / \mathrm{dt})$, and the time of end diastole (ED) was defined as the image frame containing the peak of the electrocardiographic $\mathrm{R}$-wave. Instantaneous LV volume was calculated from the epicardial LV markers with the use of a space-filling multiple tetrahedral volume method for each frame (ie, every $16.7 \mathrm{~ms}$ ). Stroke volume was calculated as the difference between end-diastolic volume (EDV) and end-systolic volume (ESV; ie, stroke volume $=$ EDV - ESV), and ejection fraction was calculated as the difference between EDV and ESV divided by EDV. These computed marker ejection fraction values underestimate ejection fraction calculated by using ventriculography because marker-measured EDV includes LV wall myocardial mass (epicardial markers).

\section{Mitral Annular Geometry}

Mitral annular area was determined by first dividing the annulus into pie slices on the basis of the annular centroid, which were then summed to yield total annular area. The septal-lateral (S-L) diameter of the annulus was calculated as the distance between the 2 markers in the middle of the septal (anterior) and lateral (posterior) mitral annulus (Figure 1, markers 3 and 7, respectively), and the commissure-commissure (C-C) diameter was determined as the distance between markers 1 and 5 (Figure 1). Annular eccentricity was computed as C-C diameter divided by S-L diameter. Total annular perimeter was expressed as the sum of the 8 individual annular segment lengths, with the fibrous annulus represented by segments $\mathrm{D}_{2-3}$ and $\mathrm{D}_{3-4}$ and the muscular annulus denoted by the remaining 6 segments. Flexion of the septal annulus during the cardiac cycle was calculated as the orthogonal distance from the midseptal annulus (Figure 1, marker 3 ) to the least-square plane fitted to the lateral annulus (Figure 1, markers 5, 6, 7, 8, and 1), as described previously. ${ }^{14}$ For $3-\mathrm{D}$ reconstruction of mitral annular 3-D shape, a right-handed Cartesian coordinate system was used, with the origin located at the midseptal annulus marker (no. 3), the $y$-axis passing through the LV apex (positive toward the apex), the positive $\mathrm{x}$-axis directed toward the midlateral annulus such that
TABLE 1. Hemodynamics

\begin{tabular}{lccl}
\hline & Baseline & TIC & $P$ value \\
\hline $\mathrm{HR}\left(\mathrm{min}^{-1}\right)$ & $102 \pm 16$ & $115 \pm 18$ & .15 \\
$\mathrm{dP} / \mathrm{dt}(\mathrm{mm} \mathrm{Hg} / \mathrm{s})$ & $1350 \pm 219$ & $1162 \pm 374$ & .29 \\
$\mathrm{EDV}(\mathrm{mL})$ & $160 \pm 57$ & $201 \pm 67$ & .001 \\
$\mathrm{ESV}(\mathrm{mL})$ & $128 \pm 45$ & $168 \pm 55$ & .0001 \\
$\mathrm{EF}(\%)$ & $20 \pm 5$ & $16 \pm 5$ & .006 \\
SV $(\mathrm{mL})$ & $33 \pm 14$ & $34 \pm 15$ & .95 \\
LVEDP $(\mathrm{mm} \mathrm{Hg})$ & $16 \pm 6$ & $30 \pm 6$ & .017 \\
LVP $(\mathrm{mm} \mathrm{Hg})$ & $98 \pm 12$ & $96 \pm 13$ & .8 \\
\hline
\end{tabular}

Data are shown as mean $\pm 1 \mathrm{SD}$. See text for explanation about the marker-calculated low ejection fraction values.

$H R$, Heart rate; $E F$, ejection fraction; $S V$, stroke volume; $L V E D P$, LV enddiastolic pressure; LVP, maximum systolic LV pressure.

marker 7 was contained in the $\mathrm{X}-\mathrm{Y}$ plane, and the positive $\mathrm{z}$-axis directed toward the posterior commissure. The midseptal annulus was chosen as the origin because it is at the center of the fibrous annulus, which should be minimally affected by LV dilatation. These same mitral annular measurements were also determined in 7 animals during dobutamine infusion $\left(10 \mu \mathrm{g} \times \mathrm{kg}^{-1} \times \mathrm{min}^{-1}\right)$ at baseline and with TIC to assess mitral annular dynamic 3-D geometry under stress conditions.

\section{Statistical Analysis}

All data are reported as means $\pm 1 \mathrm{SD}$, unless otherwise stated. Hemodynamic and marker-derived data from 3 consecutive steady-state beats were aligned at $\operatorname{ED}(\mathrm{t}=0)$, and data from the 3 beats were averaged for each of the 9 animals. The data (time aligned at ED) were analyzed from 20 frames before to 20 frames after ED, thereby allowing evaluation of the studied variables over the entire cardiac cycle. Data were compared by using the Student $t$ test for paired observations.

\section{Results}

The average animal weight was $79 \pm 10 \mathrm{~kg}$. Average cardiopulmonary bypass time was $90 \pm 27$ minutes, with a mean aortic crossclamp time of $55 \pm 7$ minutes. Correct marker position was confirmed in all animals at postmortem examination. Hemodynamic variables before and after development of cardiomyopathy are shown in Table 1. Consistent with development of TIC, rapid pacing markedly increased LV end-systolic and end-diastolic size and enddiastolic pressure.

\section{Mitral Regurgitation}

Before rapid pacing, one animal had mild MR, and 2 animals had trace MR; the others had no MR. After pacing, 4 animals had mild-to-moderate MR, 2 had moderate MR, 2 had moderate-to-severe MR, and 1 had severe MR. Overall MR grade increased from $0.2 \pm 0.3$ to $2.2 \pm 0.9(P=$ $.0001)$.

\section{Mitral Annular Geometry}

Mitral annular area, S-L and C-C diameter, and total, muscular, and fibrous annular perimeter during the cardiac cycle 

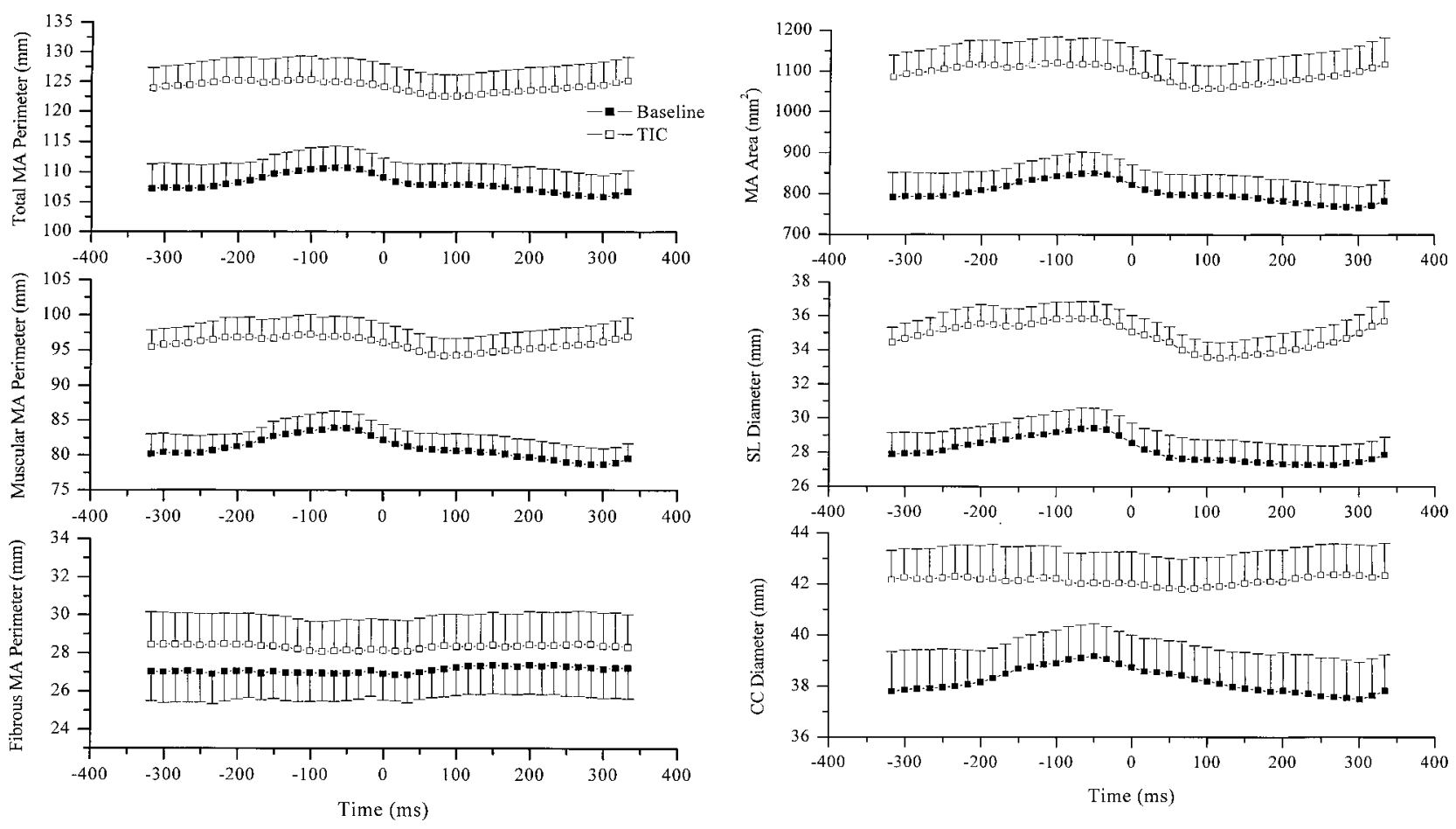

Figure 2. Mitral annular (MA) total perimeter, muscular perimeter, fibrous perimeter (left), mitral annular area, annular S-L diameter, and annular C-C diameter (right) at baseline (filled squares) and after TIC (open squares). A 650-ms time window centered at ED $(t=0)$ is illustrated for all variables. Error bars indicate 1 SEM.

are shown in Figure 2. All these annular parameters were greater throughout the cardiac cycle after the development of TIC. Table 2 summarizes annular area, S-L and C-C diameter, total perimeter, and eccentricity with TIC at ED and ES. Of note is the impressive increase with TIC in mitral annular area and, in particular, the more than double fractional increase in annular S-L diameter compared with $\mathrm{C}-\mathrm{C}$ diameter at both time points. This disproportional increase in S-L diameter decreased annular eccentricity and resulted in a more circular shape of the mitral annulus with cardiomyopathy. Mitral annular area change from maximum to minimum during the cardiac cycle was greater at baseline than with TIC $(12.0 \% \pm 7 \%$ vs $8.5 \% \pm 5.7 \%, P=$ $.06)$.

\section{Mitral Annular Dynamics Under Stress}

During dobutamine infusion, similar hemodynamics were observed at baseline and with TIC in terms of heart rate $\left(146 \pm 15\right.$ vs $165 \pm 23$ beats $/ \mathrm{min}^{-1}$, baseline vs TIC; $P=$ .1), $\mathrm{LV} \mathrm{dP} / \mathrm{dt}_{\max }(3263 \pm 780 \mathrm{vs} 2518 \pm 609 \mathrm{~mm} \mathrm{Hg} / \mathrm{s}, P=$ .1), LV stroke volume ( $35 \pm 16$ vs $37 \pm 16 \mathrm{~mL}, P=.4)$, and peak $\mathrm{LV}$ pressure $(131 \pm 11$ vs $124 \pm 15 \mathrm{~mm} \mathrm{Hg}, P=$ .4). Mitral annular area during inotropic stimulation at baseline and with TIC is shown in Figure 3. Dobutamine induced greater mitral annular area reduction at baseline than in TIC conditions at both $\mathrm{ED}(12.8 \% \pm 9.6 \%$ vs $2.9 \% \pm$
$4.1 \%, P=.04)$ and ES $(15.5 \% \pm 9.4 \%$ vs $4.8 \% \pm 4.3 \%$, $P=.01)$, indicating blunted mitral annular response to inotropic stimulation in cardiomyopathy. During dobutamine infusion, mitral annular area in TIC was $51 \% \pm 19 \%$ and $64 \% \pm 20 \%$ greater than baseline numbers at $\mathrm{ED}$ and ES, respectively.

\section{Regional Mitral Annular Dynamics}

Table 3 summarizes baseline and TIC end-diastolic lengths, as well as length reduction (percentage) from diastolic maximum to systolic minimum of each of the 8 annular segments. With the exception of $\mathrm{D}_{3-4}$, all annular segments lengthened at ED with TIC. Interestingly, segment $\mathrm{D}_{2-3}$, which with segment $\mathrm{D}_{3-4}$ corresponds to the fibrous annulus, underwent a small but significant increase in length, suggesting that the fibrous annulus was also dilating with cardiomyopathy. Reduction of segment lengths in the septal annulus during the cardiac cycle did not change with TIC, whereas reduction of all lateral annular segments decreased significantly. Thus the most dynamic portion of the mitral annulus, the lateral annulus, was affected to the greatest extent by cardiomyopathy.

\section{3-D Mitral Annular Shape}

Figure 4 shows the mitral annular 3-D shape at both ED and ES before and after TIC. The larger end-diastolic mitral 
TABLE 2. Mitral annular geometry

\begin{tabular}{|c|c|c|c|c|}
\hline & Baseline & TIC & Change (\%) & $P$ value \\
\hline \multicolumn{5}{|c|}{ MA area $\left(\mathrm{mm}^{2}\right)$} \\
\hline ED & $817 \pm 146$ & $1100 \pm 161$ & $36 \pm 14$ & .00001 \\
\hline ES & $761 \pm 150$ & $1099 \pm 157$ & $46 \pm 13$ & .00001 \\
\hline \multicolumn{5}{|c|}{ MA perimeter (mm) } \\
\hline ED & $108.9 \pm 9.8$ & $124.2 \pm 10.1$ & $14 \pm 5$ & .00001 \\
\hline ES & $105.5 \pm 10.6$ & $124.5 \pm 9.8$ & $18 \pm 5$ & .00001 \\
\hline \multicolumn{5}{|c|}{$\mathrm{S}-\mathrm{L}$ diameter $(\mathrm{mm})$} \\
\hline ED & $28.2 \pm 3.5$ & $35.1 \pm 2.6$ & $25 \pm 12$ & .00002 \\
\hline ES & $27.2 \pm 3.2$ & $34.9 \pm 2.6$ & $29 \pm 10$ & .00001 \\
\hline \multicolumn{5}{|c|}{ C-C diameter (mm) } \\
\hline ED & $38.9 \pm 3.7$ & $42.1 \pm 3.3$ & $9 \pm 5$ & .0014 \\
\hline ES & $37.4 \pm 4.2$ & $42.3 \pm 3.2$ & $14 \pm 6$ & .00001 \\
\hline \multicolumn{5}{|c|}{ MA eccentricity (C-C/S-L) } \\
\hline ED & $1.37 \pm 0.16$ & $1.20 \pm 0.06$ & $12 \pm 8$ & .004 \\
\hline ES & $1.37 \pm 0.11$ & $1.21 \pm 0.05$ & $11 \pm 6$ & .0008 \\
\hline
\end{tabular}

Data are shown as mean \pm 1 SD.

$M A$, Mitral annulus; $S$ - $L$, septal-lateral; $C$ - $C$, commissure-commissure.

annular area with cardiomyopathy was accentuated at ES because of decreased reduction of the lateral annular segments with TIC. The annulus had a similar 3-D geometry at baseline and with TIC both at ED and ES, with the "saddle horn" (marker 3) elevated above an otherwise relatively planar annulus. The end-diastolic distance from each annular marker to an annular plane fitted to all annular markers at baseline and with TIC is shown in Figure 5. There was some flattening of the midseptal annulus (decrease in the end-diastolic distance from marker 3 to the mitral annular plane from $3.3 \pm 1.0$ to $2.5 \pm 1.3 \mathrm{~mm}, P=.03$ ) and displacement below the annular plane of the midlateral annulus (marker 7) after the development of TIC. Enddiastolic distance of the midseptal marker (marker 3) to the annular plane did not change during dobutamine infusion either at baseline $(3.3 \pm 1.0$ vs $3.2 \pm 0.9 \mathrm{~mm}, P=.7)$ or with TIC $(2.5 \pm 1.3$ vs $2.9 \pm 1.2 \mathrm{~mm}, P=.12)$, which implies independence of the septal annular height and inotropic state. Figure 6 shows the dynamics of this annular flexion distance, which decreased in TIC relative to baseline at $\mathrm{ED}(5.5 \pm 1.4$ vs $4.4 \pm 2.4 \mathrm{~mm}, P=.005)$ and at $\mathrm{ES}$ $(8.0 \pm 1.7$ vs $6.2 \pm 2.6 \mathrm{~mm}, P=.03)$, further suggesting "saddle horn" flattening in cardiomyopathy. Annular flexion (as defined by the change in this distance from ED to ES ${ }^{14}$ ), however, did not change significantly with TIC $(2.2 \pm 1.1$ and $1.8 \pm 0.7 \mathrm{~mm}$ for baseline and TIC, respectively; $P=$ .5). Annular flexion was not affected by inotropic stimulation either at baseline $(2.6 \pm 0.8$ and $3.5 \pm 1.4 \mathrm{~mm}$ before and after dobutamine, respectively; $P=.3$ ) or with cardiomyopathy $(1.7 \pm 0.8$ and $2.0 \pm 0.8 \mathrm{~mm}$ before and after dobutamine, respectively; $P=.5$ ).

\section{Discussion}

Mitral ring annuloplasty in patients with dilated cardiomyopathy has been shown to reduce MR and improve survival in this challenging patient population. ${ }^{8,15}$ Details of the 3-D perturbations in mitral annular geometry associated with end-stage dilated ventricles and MR, however, have not been clearly defined, and this knowledge could not only shed light on the mechanisms of MR but also provide a basis for the design of better reparative techniques. In the current study, using radiopaque markers and TIC as a model of dilated cardiomyopathy, we found significant annular dilatation (especially in the S-L dimension) and perturbed contraction of lateral annular segments to be associated with TIC. The 3-D annular shape and septal annular flexion were maintained in cardiomyopathy, but flattening of the "saddle horn" (midseptal annulus) was observed in TIC.

The extent of annular dilatation in this study is similar to the approximately $30 \%$ increase in mitral annular area reported in patients with dilated cardiomyopathy relative to normal control subjects, ${ }^{6}$ and the $12 \%$ annular area reduction during the cardiac cycle at baseline is similar to the $13 \%$ annular area reduction in sheep reported by others. ${ }^{3,16}$ Annular dilatation alone has been suggested to result in MR in cardiomyopathy, ${ }^{5}$ and an isolated increase of annular perimeter by $25 \%$ with an externally adjustable ring has been shown to cause moderate-to-severe MR in experimental animals. ${ }^{17}$

Furthermore, similar annular perimeter increase, as seen in the present study, has been reported to result in incomplete mitral leaflet coaptation in a finite element analysis of mitral dilatation in a computational model. ${ }^{18}$ Thus TIC led to annular area and perimeter changes consistent with the development of MR.

Analysis of individual annular segment dynamics revealed longer end-diastolic length of all segments of the muscular annulus and one segment of the fibrous annulus. Although length increase in the fibrous annular segment was only modest, this is a finding that confronts surgical dogma 


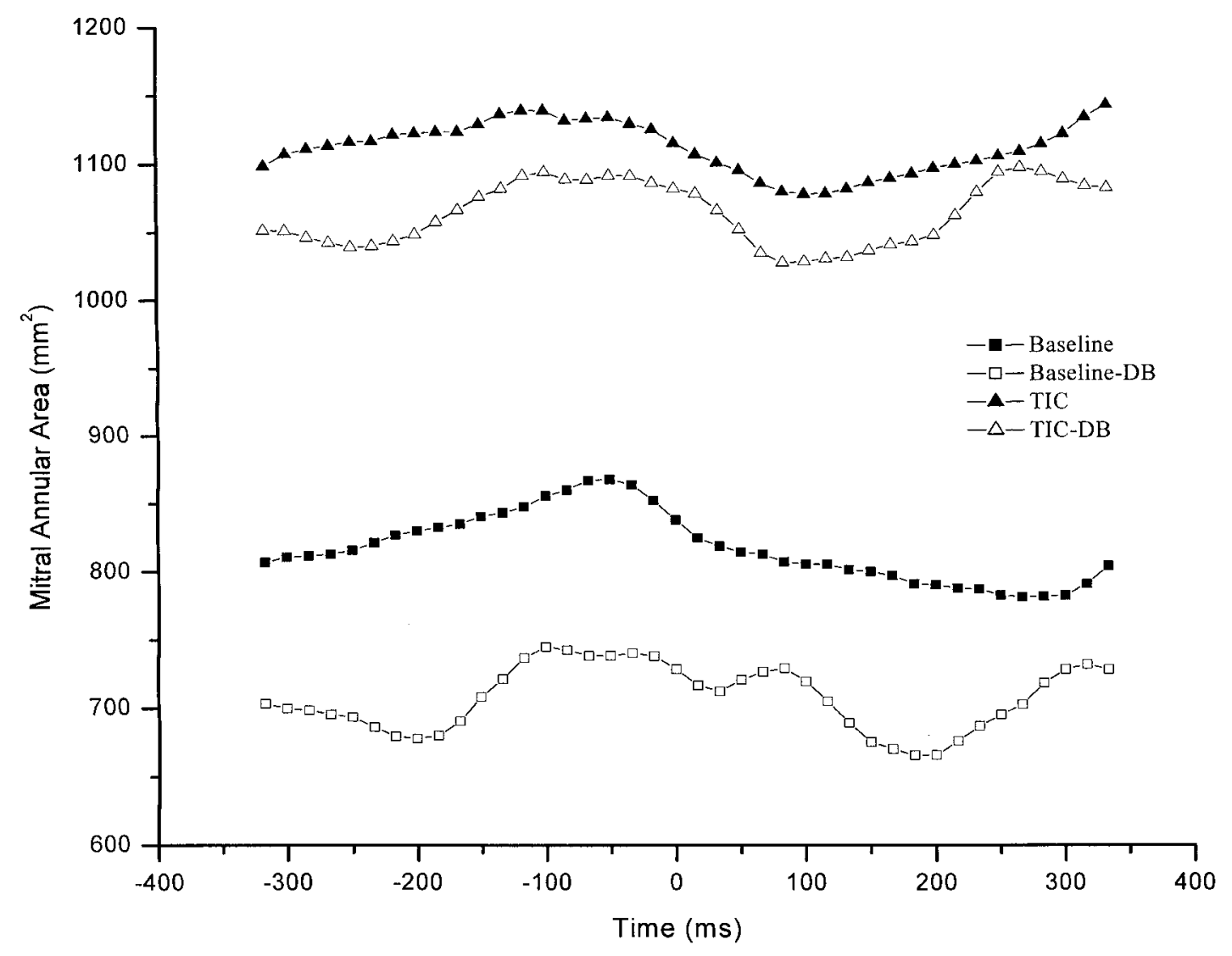

Figure 3. Mitral annular area at baseline (squares) and with TIC (triangles) before (filled symbols) and after (open symbols) dobutamine (DB) infusion. A 650-ms time window centered at ED $(t=0)$ is shown for all variables.

TABLE 3. Regional mitral annular dynamics

\begin{tabular}{|c|c|c|c|c|c|}
\hline & \multirow[b]{2}{*}{ Segment no. } & \multicolumn{2}{|c|}{ End-diastolic length (mm) } & \multicolumn{2}{|c|}{ Length change (\%) } \\
\hline & & Baseline & TIC & Baseline & TIC \\
\hline \multirow[t]{4}{*}{ Septal annulus } & $D_{1-2}$ & $13.3 \pm 3.6$ & $15.0 \pm 4.3 \ddagger$ & $9.6 \pm 3.2$ & $7.3 \pm 2.1$ \\
\hline & $D_{2-3}$ & $11.4 \pm 2.2$ & $12.2 \pm 2.2 \dagger$ & $9.7 \pm 2.6$ & $8.8 \pm 3.4$ \\
\hline & $D_{3-4}^{2-3}$ & $15.6 \pm 3.1$ & $15.9 \pm 3.5$ & $6.5 \pm 3.1$ & $6.8 \pm 3.1$ \\
\hline & $D_{4-5}^{3-4}$ & $13.2 \pm 1.6$ & $14.7 \pm 2.1 \dagger$ & $10.7 \pm 3.0$ & $9.3 \pm 4.3$ \\
\hline \multirow[t]{4}{*}{ Lateral annulus } & $D_{5-6}^{4-5}$ & $11.0 \pm 2.7$ & $13.0 \pm 3.1 \ddagger$ & $13.3 \pm 2.6$ & $8.4 \pm 3.5^{*}$ \\
\hline & $D_{6-7}^{5-0}$ & $13.2 \pm 3.2$ & $15.5 \pm 3.5 \ddagger$ & $13.0 \pm 4.1$ & $9.2 \pm 4.1 \dagger$ \\
\hline & $D_{7-8}^{0-1}$ & $16.4 \pm 3.2$ & $19.6 \pm 3.5 \ddagger$ & $14.0 \pm 6.9$ & $8.0 \pm 3.0^{*}$ \\
\hline & $\mathrm{D}_{8-1}$ & $14.8 \pm 5.4$ & $18.5 \pm 5.9 \ddagger$ & $13.8 \pm 5.7$ & $7.4 \pm 1.4 \dagger$ \\
\hline
\end{tabular}

Segments are labeled as distances between corresponding markers ( $i e, \mathrm{D}_{1-2}=$ distance from marker 1 to 2 [see Figure 1]). Length change is defined as the reduction in the percentage between diastolic maximum and systolic minimum length. ${ }^{*} P<.05, \uparrow P<.01, \ddagger P<.001$ versus baseline by $t$ test for paired comparisons.

because it is widely believed that the fibrous annulus does not remodel when the annulus dilates.

In prior studies the lateral annulus has been shown to be more dynamic than the septal annulus ${ }^{19}$ and more susceptible to dilatation during acute ischemia. ${ }^{2,19,20}$ Hence it is not surprising that in the current study the most dynamic annular segments comprising the lateral annulus were most af- fected by cardiomyopathy in terms of end-diastolic length increase and reduction of contraction during the cardiac cycle. Thus the lateral annulus not only underwent substantial dilatation but also a decrease in its sphincteric action, which reduces mitral annular area during the cardiac cycle. Similar decrease in annular area reduction has been reported in acute ischemia, ${ }^{2}$ varying hemodynamic conditions, ${ }^{1}$ and 

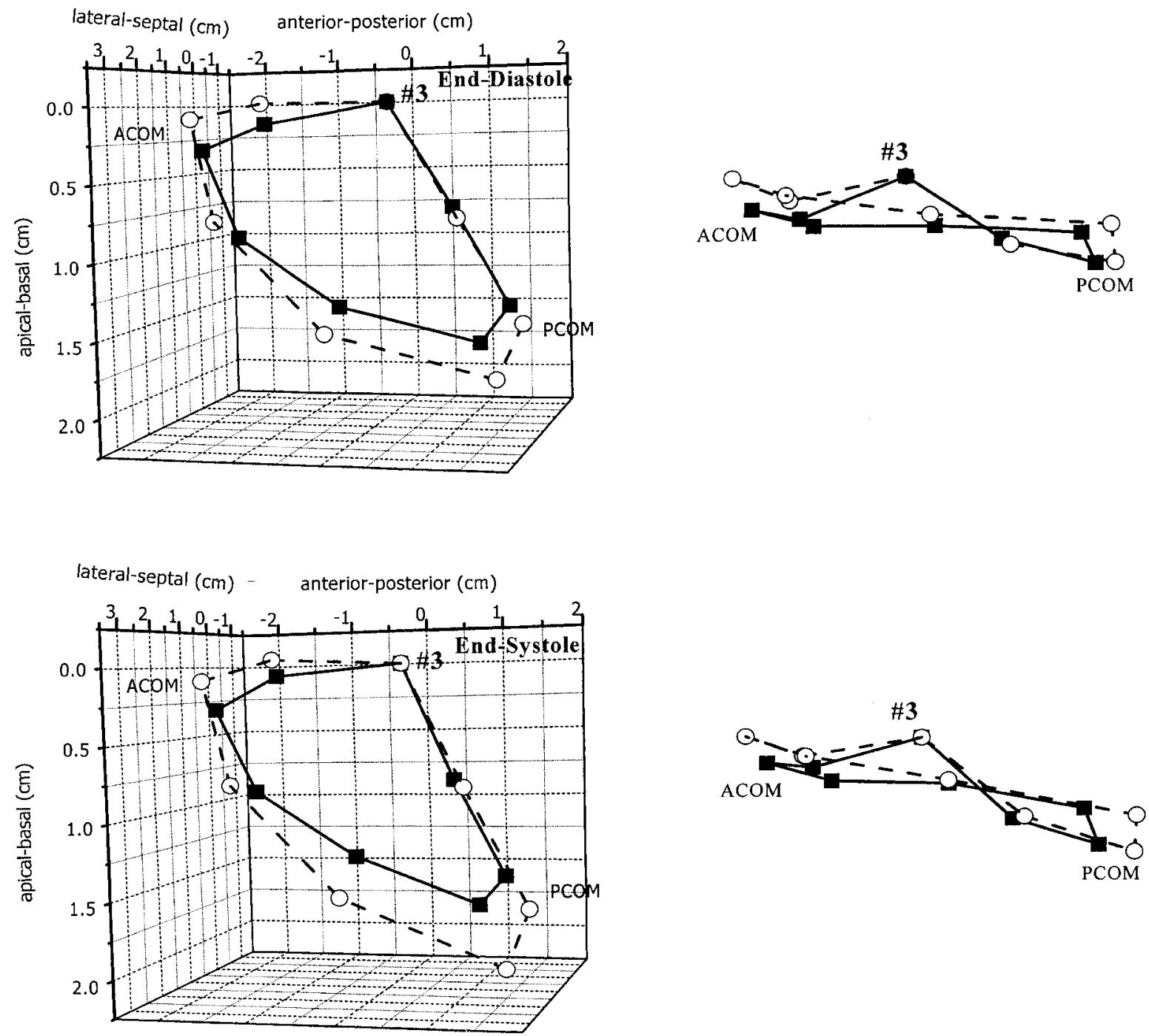

Figure 4. Left, Three-dimensional reconstruction of the mitral annulus at ED (top) and ES (bottom) at baseline (filled squares) and after TIC (open circles). Right, Rotated view of each reconstruction as viewed from the lateral-septal annulus to illustrate the saddle shape of the annulus. \#3, Saddle horn marker; ACOM, anterior commissure; PCOM, posterior commissure.

ventricular pacing. ${ }^{3}$ Interestingly, during dobutamine infusion, annular area at baseline was considerably reduced, as described previously, ${ }^{21}$ but only slightly in TIC. Mitral annular response to inotropic stimulation appeared blunted in TIC, which would further compromise the annular sphincteric mechanism. These findings might have implications for valvular competence in patients with cardiomyopathy during stress conditions.

The saddle shape of the mitral annulus ${ }^{22}$ was observed at baseline and with TIC, which correlates with the findings in recent echocardiographic studies in patients with dilated ${ }^{6}$ and ischemic ${ }^{23}$ cardiomyopathy. At baseline, the end-diastolic distance from the midseptal annulus ("saddle horn") to the least-squares plane of the mitral annulus was $3.3 \pm$
$1.0 \mathrm{~mm}$, a distance almost identical to the $3.9 \pm 1.5 \mathrm{~mm}$ reported in human subjects by using magnetic resonance imaging. ${ }^{24}$ Flattening of the midseptal annulus occurred in TIC and is in accordance with clinical findings. ${ }^{6,23}$ The amount of annular flexion before pacing was somewhat smaller than in the human annulus ${ }^{14}$ and did not change with TIC. Furthermore, neither annular flexion nor displacement of the annular "saddle horn" from the annular plane appeared to be dependent on inotropic state.

\section{Surgical Implications}

Mitral ring annuloplasty with different methods has been used to correct mitral insufficiency in patients with cardiomyopathy, ${ }^{8,25}$ yet the optimal form of annular repair re- 


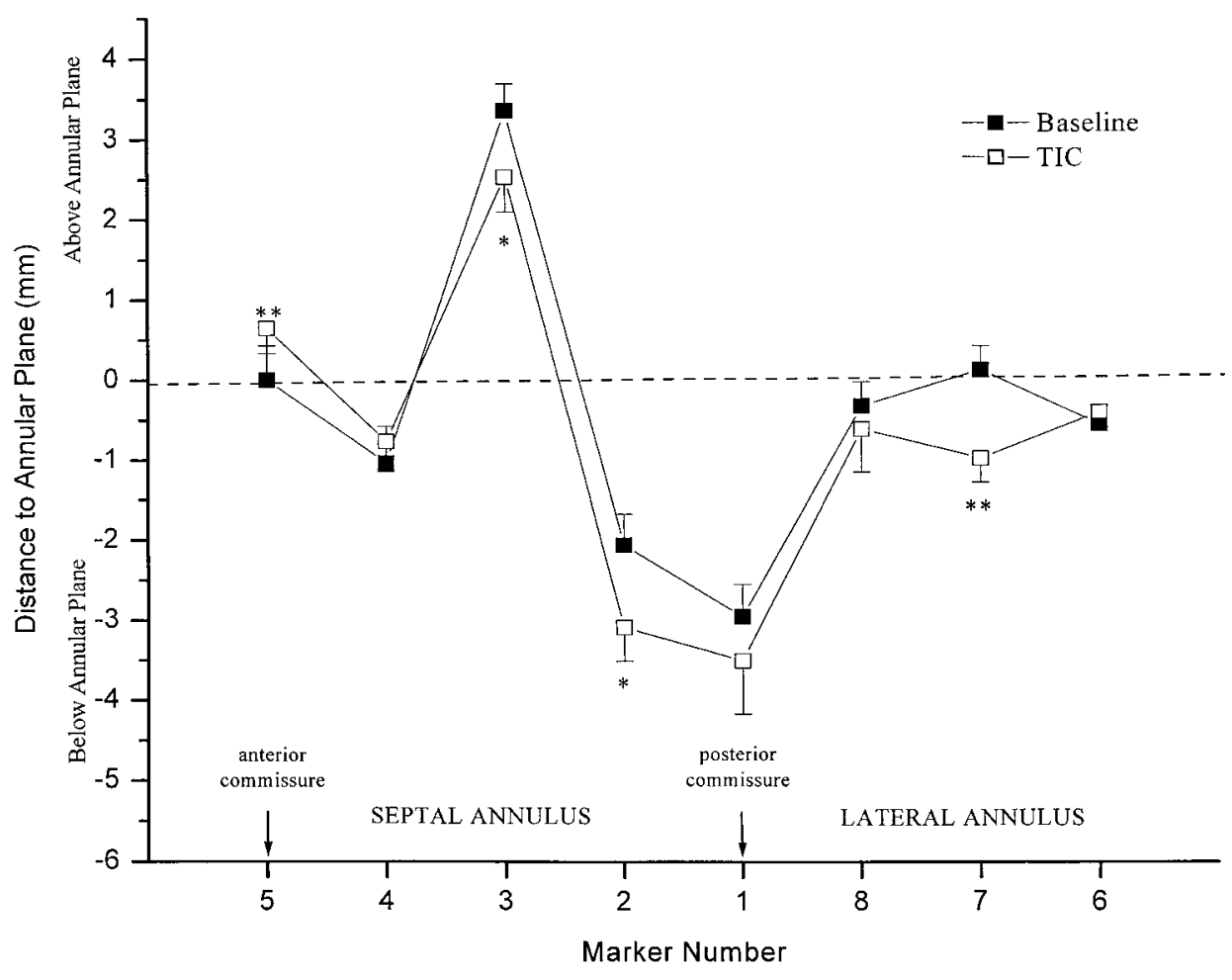

Figure 5. End-diastolic distance of each annular marker from the least-squares plane fitted to all annular markers before (filled squares) and after (open squares) development of TIC. Marker numbers, as shown in Figure 1. Error bars indicate 1 SEM. ${ }^{*} P<.05$ and ${ }^{* *} P<.01$ by means of $t$ test for paired comparisons.

mains elusive because little is known about the annular dynamic 3-D geometry in cardiomyopathic conditions and how it differs from normal. The current study suggests that S-L annular dilatation is chiefly responsible for the substantial mitral annular area increase associated with cardiomyopathy and MR. This implies that clinical approaches to treat MR in dilated cardiomyopathy should first and foremost reduce this dimension to enhance more leaflet coaptation. Because the fibrous annulus also dilated in TIC, our data support making the entire annulus smaller to prevent further dilatation of the fibrous annulus, which could in turn affect durability of the repair by contributing to subsequent annular S-L dilatation. The mitral annulus became more circular in TIC, and re-establishing the traditional 3:4 systolic ratio of S-L to C-C mitral annular diameters, as advocated by Carpentier and coworkers, ${ }^{26}$ might be important. Indeed, some annuloplasty rings are designed in this configuration. Furthermore, because the annulus flattens in cardiomyopathy, a repair that retains the natural saddle shape of the annulus could be desirable. It is speculative whether repair on the basis of these theoretic guidelines would lead to improved or more durable clinical results; further studies are needed to characterize more precisely mitral annular dynamic 3-D geometry in normal human subjects and in patients with dilated or ischemic cardiomyopathy.

\section{Limitations}

Several limitations of this study must be emphasized before extrapolating these observations to the clinical context. Myocardial marker studies require suturing miniature tantalum markers to the cardiac structures of interest, and the presence and collective mass of the markers might alter normal annular motion. The markers used in this study, however, were very light (4-8 mg) and would not be expected to affect the normal dynamics of the mitral annulus. Interspecies differences in annular anatomy ${ }^{27}$ might limit the clinical relevance of these data, but human and ovine annular dynamics are similar during the cardiac cycle.,3,28 Finally, although a rapid pacing cardiomyopathy preparation offers a good model of human congestive heart failure, ${ }^{10,11}$ it does not precisely mimic all the clinical changes seen in dilated cardiomyopathy. Finally, immediately after cessation of rapid pacing, biochemical, neurohumoral, morphologic, and functional parameters quickly begin to return to normal. ${ }^{29}$ This probably did not affect the data obtained in this experiment because the TIC measurements were obtained within minutes after cessation of pacing.

We appreciate the superb technical assistance provided by Mary K. Zasio, BA, Carol W. Mead, BA, Erin M. Schultz, BS, and Maggie Brophy, AS. 


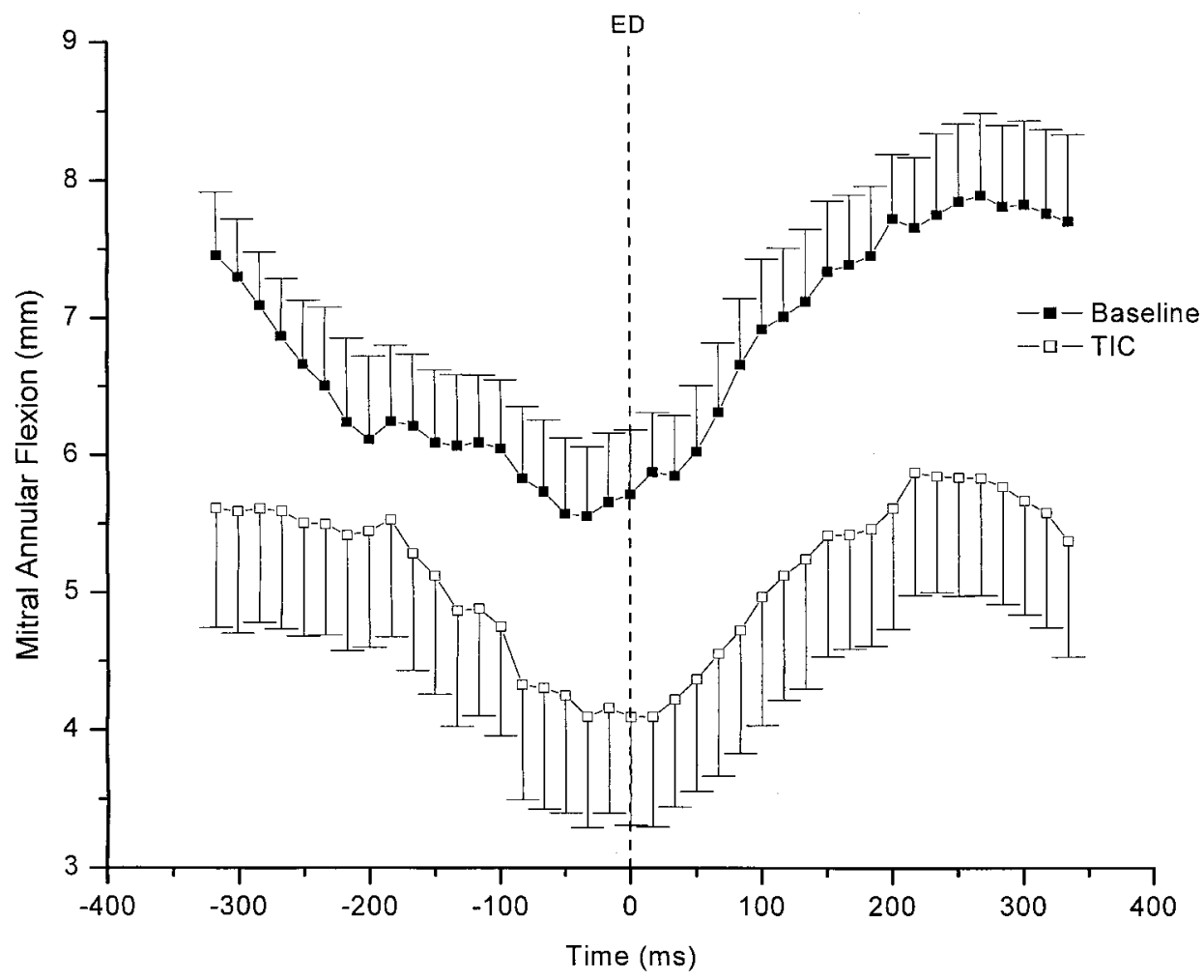

Figure 6. Septal annulus flexion expressed as the distance of the saddle horn marker to the least-squares plane of the lateral annulus before (filled squares) and after (open squares) TIC. A 650-ms time window centered at ED (dashed line) is shown. Error bars indicate 1 SEM.

\section{References}

1. Tsakiris AG, Von Bernuth G, Rastelli GC, Bourgeois MJ, Titus JL, Wood EH. Size and motion of the mitral valve annulus in anesthetized intact dogs. J Appl Physiol. 1971;30:611-8.

2. Glasson JR, Komeda M, Daughters GT, Bolger AF, Karlsson MO, Foppiano LE, et al. Early systolic mitral leaflet "loitering" during acute ischemic mitral regurgitation. J Thorac Cardiovasc Surg. 1998; 116:193-205.

3. Glasson JR, Komeda M, Daughters GT, Foppiano LE, Bolger AF, Tye TL, et al. Most ovine mitral annular 3-D size reduction occurs before ventricular systole and is abolished with ventricular pacing. Circulation. 1997;96:II115-23.

4. Timek TA, Lai DT, Dagum P, Green GR, Glasson JR, Daughters GT, et al. Mitral annular dynamics during rapid atrial pacing. Surgery. 2000;128:361-7.

5. Boltwood CM, Tei C, Wong M, Shah PM. Quantitative echocardiography of the mitral complex in dilated cardiomyopathy: the mechanism of functional mitral regurgitation. Circulation. 1983;68:498-508.

6. Flachskampf FA, Chandra S, Gaddipatti A, Levine RA, Weyman AE, Ameling W, et al. Analysis of shape and motion of the mitral annulus in subjects with and without cardiomyopathy by echocardiographic 3-dimensional reconstruction. J Am Soc Echocardiogr. 2000;13:27787.

7. Kaplan SR, Bashein G, Sheehan FH, Legget ME, Munt B, Li XN, et al. Three-dimensional echocardiographic assessment of annular shape changes in the normal and regurgitant mitral valve. Am Heart J. 2000;139:378-87.

8. Bolling SF, Pagani FD, Deeb GM, Bach DS. Intermediate-term outcome of mitral reconstruction in cardiomyopathy. J Thorac Cardiovasc Surg. 1998;115:381-8.
9. Power JM, Raman J, Dornom A, Farish SJ, Burrell LM, Tonkin AM, et al. Passive ventricular constraint amends the course of heart failure: a study in an ovine model of dilated cardiomyopathy. Cardiovasc Res. 1999;44:549-55.

10. Coleman HM, Pool PE, Whipple GH, Covell JW, Ross J, Braunwald E. Congestive heart failure following chronic tachycardia. Am Heart J. 1971;81:790-8.

11. Wilson JR, Hickey WF, Lanoce V, Ferraro N, Muhammad A, Reichek $\mathrm{N}$. Experimental congestive heart failure produced by rapid ventricular pacing in the dog: cardiac effect. Circulation. 1987;75:857-67.

12. Riegger AJG. The renin-angiotensin-aldosterone system, antidiuretic hormone and sympathetic nerve activity in an experimental model of congestive heart failure in the dog. Clin Sci (Colch). 1982;62:465-9.

13. Daughters GT, Miller DC, Schwartzkopf A, Mead CW, Ingels NB. A comparison of two analytical systems for three-dimensional reconstruction from biplane videoradiograms. IEEE Comput Cardiol. 1989; 15:79-82.

14. Komoda T, Hetzer R, Oellinger J, Siniawski H, Hofmeister J, Hubler $\mathrm{M}$, et al. The inflexible mitral annulus after valve prosthesis. Inherent risk of dynamic left ventricular outflow tract obstruction. ASAIO J. 1996;42:M372-5.

15. Chen FY, Adams DH, Aranki SF, Collins JJ Jr, Couper GS, Rizzo RJ, et al. Mitral valve repair in cardiomyopathy. Circulation. 1998;98: II124-7.

16. Gorman JH, Jackson BM, Gorman RC, Kelley ST, Gikakis N, Edmunds LH Jr. Papillary muscle discoordination rather than increased annular area facilitates mitral regurgitation after acute posterior myocardial infarction. Circulation. 1997;96:II124-7.

17. Ahmadi A, Spillner G, Johannesson T. Hemodynamic changes following experimental production and correction of acute mitral regur- 
gitation with an adjustable ring prosthesis. Thorac Cardiovasc Surg. 1988;36:313-9.

18. Kunzelman KS, Cochran RP. Annular dilatation increases stress in the mitral valve and delays coaptation: a finite element computer model. Cardiovasc Surg. 1997;5:427-34.

19. Glasson JR, Komeda MK, Daughters GT, Niczyporuk MA, Bolger $\mathrm{AF}$, Ingels $\mathrm{NB}$, et al. Three-dimensional regional dynamics of the normal mitral annulus during left ventricular ejection. $J$ Thorac Cardiovasc Surg. 1996;111:574-85.

20. Gorman JH, Gorman RC, Jackson BM, Hiramatsu Y, Gikakis N, Kelley ST, et al. Distortions of the mitral valve in acute ischemic mitral regurgitation. Ann Thorac Surg. 1997;64:1026-31.

21. Gorman JH, Jackson BM, Kelley ST, Melekan R, Edmunds LH Jr. Effect of inotropic state on the size of the mitral valve annulus. Surg Forum. 1997;48:275-8.

22. Levine RA, Handschumacher MD, Sanfilippo AJ, Hagege AA, Harrigan $\mathrm{P}$, Marshall JE, et al. Three-dimensional echocardiographic reconstruction of the mitral valve, with implications for the diagnosis of mitral valve prolapse. Circulation. 1989;80:589-98.
23. Kaplan SL, Sullivan SF, Malm JR, Bowman F Jr, Papper EM. Effect of cardiac bypass on pulmonary diffusing capacity. $J$ Thorac Cardiovasc Surg. 1969;57:738-46.

24. Komoda T, Hetzer R, Uyama C, Siniawski H, Maeta H, Rosendahl UP, et al. Mitral annular function assessed by 3D imaging for mitral valve surgery. J Heart Valve Dis. 1994;3:483-90.

25. Bishay ES, McCarthy PM, Cosgrove DM, Hoercher KJ, Smedira NG, Mukherjee D, et al. Mitral valve surgery in patients with severe left ventricular dysfunction. Eur J Cardiothorac Surg. 2000;17:213-21.

26. Carpentier AF, Lessana A, Relland JY, Belli E, Mihaileanu S, Berrebi AJ, et al. The "physio-ring": an advanced concept in mitral valve annuloplasty. Ann Thorac Surg. 1995;60:1177-86.

27. Walmsley R. Anatomy of human mitral valve in adult cadaver and comparative anatomy of the valve. Br Heart J. 1978;40:351-66.

28. Ormiston JA, Shah PM, Tei C, Wong M. Size and motion of the mitral valve annulus in man. I. A two-dimensional echocardiographic method and findings in normal subjects. Circulation. 1981;64:113-20.

29. Shinbane JS, Jensen DN, Ellenbogen KA, Fitzpatrick AP, Scheinman MM. Tachycardia-induced cardiomyopathy: a review of animal models and clinical studies. J Am Coll Cardiol. 1997;29:709-15.

\section{Bound volumes available to subscribers}

Bound volumes of The Journal of Thoracic and Cardiovascular Surgery are available to subscribers (only) for the 2003 issues from the Publisher, at a cost of $\$ 134.00$ for domestic, $\$ 165.85$ for Canadian, and $\$ 155.00$ for international subscribers for Vol 125 (January-June) and Vol 126 (July-December). Shipping charges are included. Each bound volume contains a subject and author index and all advertising is removed. The binding is durable buckram with the Journal name, volume number, and year stamped in gold on the spine. Payment must accompany all orders. Contact Mosby, Subscription Customer Service, 6277 Sea Harbor Dr, Orlando, FL 32887, USA; phone 800-654-2452 or 407-345-4000.

Subscriptions must be in force to qualify. Bound volumes are not available in place of a regular Journal subscription. 